\title{
A METHODOLOGY TO INCREASE THE LEVEL OF THE "EFFECTIVE COMMUNICATION" COMPETENCE IN MASTER DEGREE
}

\author{
Juan-José Alfaro-Saiz, Maria-José Verdecho, Pedro Gómez-Gasquet, Raúl \\ Rodríguez-Rodríguez
}

Department of Business Organization, Universitat Politècnica de València (SPAIN)

\begin{abstract}
One of the main objectives of the competences evaluation program in universities is to increase the level that their students have in these competences. There are descriptive guides recommending procedures for assessing these competencies and also to collect evidence of such assessments that help to evaluate the progress made. However, it is not so common to use active methodologies to guide this process from a practical and systemic point of view. This paper describes a methodology that helps to increase the level of competence "effective communication" in its oral dimension focused on the master students. The methodology consists of a series of phases that allow improving step by step and incrementally the level of competence acquired. It also describes the recommended assessment procedure to assess the progress and the set of associated actions that the student must follow to improve the competence. The methodology is designed to allow an individualized monitoring of the progress of each student based on the predefined objectives and takes into account their initial level. The methodology will be applied during the next academic year in a course of the master in Advanced Engineering Production, Logistics and Supply Chain at the Higher Technical School of Industrial Engineering (Universitat Politècnica de València).
\end{abstract}

Keywords: Methodology, Effective communication, Oral dimension, Master students.

\section{INTRODUCTION}

The vast majority of fundamental competencies that students must develop in their respective degrees and postgraduate courses are evaluated in one way or another. However, there is sometimes an absence of methods to help increase these competencies. In the case of this work we will focus on the masters studies, and in particular on the effective communication competence in its oral dimension. This competence is very important for several reasons. Postgraduate students should be prepared to work at a managerial level.

At this level, achieving a high performance in oral communication is almost essential. It is usual to coordinate working groups effectively, expose strategic and tactical plans to multiple people, negotiate all types of contracts, present business scenarios, budgets, etc. Any of these situations requires a high level of competence "effective communication", in its oral dimension, and therefore, such competence must be trained in the field of postgraduate studies.

In this sense, this paper describes a methodology that helps to increase the level of competence "effective communication" in its oral dimension focused on the master students. The methodology consists of a series of phases that allow improving step by step and incrementally the level of competence acquired. It also describes the recommended assessment procedure to assess the progress and the set of associated actions that the student must follow to improve the competence. . The methodology is designed to allow an individualized monitoring of the progress of each student based on the predefined objectives and takes into account their initial level. Some approaches to address this competence had been developed by other authors, instructors and Universities [1], [2], [3], [4], [5], etc.

The methodology will be applied during the next academic year in a course of the master in Advanced Engineering Production, Logistics and Supply Chain at the Higher Technical School of Industrial Engineering (Universitat Politècnica de València)

The following section presents the methodology developed and finally the conclusions. 


\section{METHODOLOGY}

The methodology developed consists of three main stages (Figure 1) that are very simple and easy to apply: 1. Current level; 2. Objective to Achieve; and 3. Actions to follow. Efforts have been made to maximize the practical application of the three stages, so that students can take advantage of the work they do and quickly obtain tangible results.

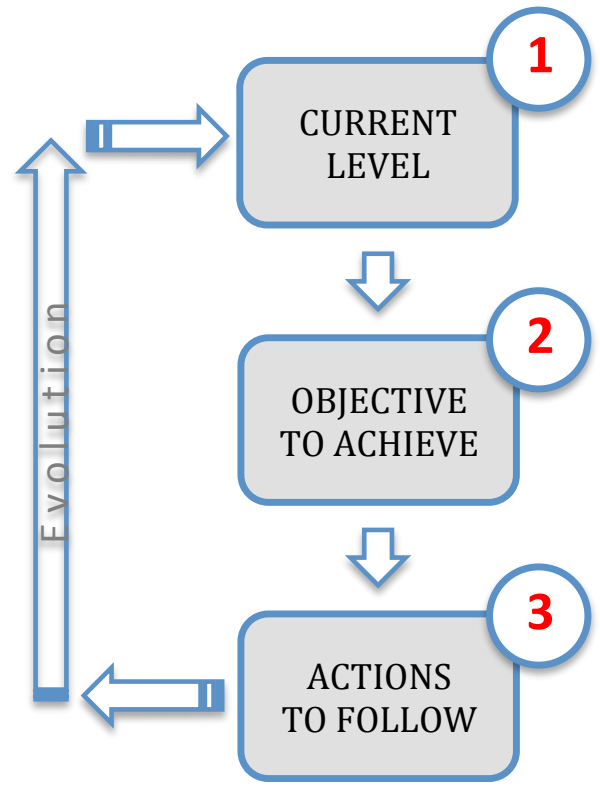

Figure 1. Methodology.

The stages of the methodology are described below.

1 Current Level (Figure 2).

This first stage is to evaluate the current level that the student has in the competence effective communication (oral dimension). It is basic to know which is the starting point of this competence, the asymmetries between students are sometimes quite important. Thus, while some students have a medium-high level, others have important deficiencies. Therefore, knowing the starting level facilitates the use of time spent in the rest of subsequent stages. In addition, if the starting level is low it is not easy to reach a high level quickly, so it is important to adapt the actions to be followed according to the starting level (individualized progress).

The evaluation is based on an oral presentation by the student of some of the subjects, works or contents established in the subject of study. It is not necessary for the student to devote excessive time in the preparation of the theoretical contents to be presented. It is simply a dissertation to evaluate what is the starting point of all the possible skills that encompasses the oral dimension of communication. In this sense, a number of skills have been established that are not excessive to evaluate but broad enough to give a more general view of the skills of such competence. Some of the skills to take into account are: body posture, physical situation of the student in the classroom, voice modulation, fixation of the gaze, repetition of verbal expressions, variety of language, emphasis on important aspects, relaxation in expression body, etc.

It is advisable that the presentation is made to several colleagues and the teacher, in this way the number of evaluations will be greater and the perception of the level of the different skills of oral communication will be, a priori, better evaluated. It is imperative that the students who are going to carry out the evaluation of their partner have performed the previous self-training that will be described in the third stage. This is due to the difficulty of students to assess the dimensions of oral communication, if they do not previously know what should be understood by a good dissertation, and what scale allows it to measure.

Once the presentation is finished, the evaluation is carried out through a survey composed of 12 items that allow assessing the most important skills of oral communication. The scale is "Likert" type. To complete the survey is developing an online tool that facilitates the treatment of all scores anonymously. The results are stored directly on the personal page of the evaluated 
student, in a personal way, so no one else can have access to such information. The result is broken down into several scores based on each skill assessed and also a general aggregate score. Each score is located on a tabular chart showing the level based on the scale: beginner, intermediate or advanced.

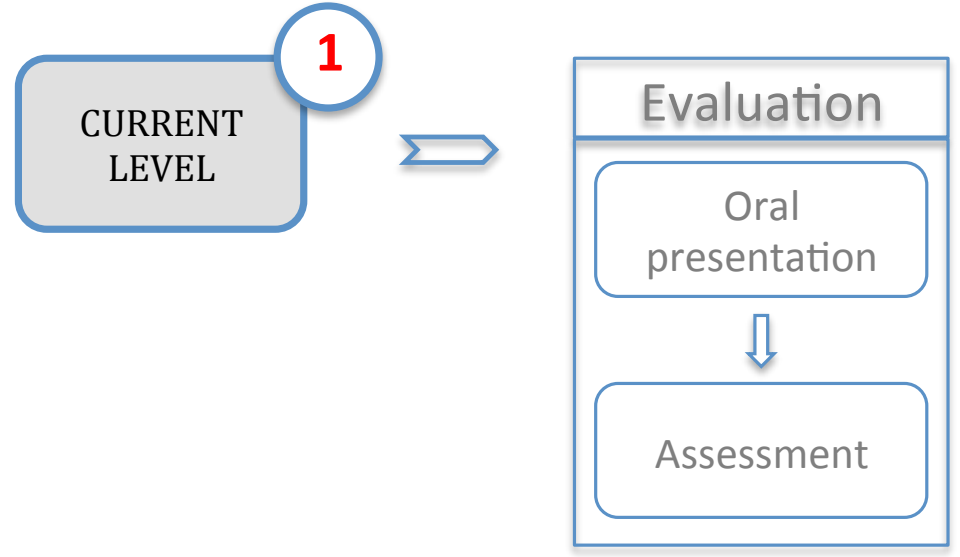

Figure 2. Stage 1: Current level.

2 Objective to achieve (Figure 3).

This second stage starts with the score obtained in the previous stage, in which the student already knows, in a general way, and also in a particular way, in each skill what his level is.

From here, the student decides whether he wants to globally improve the competition, or if he wants to focus on one or more skills in which he has greater weaknesses. The tool, once selected the skills, suggests a target to reach, although it is the student that validates or changes that target. Depending on the targets selected for each skill or a general target of the entire competition, the actions to be taken to increase the level of competition are defined.

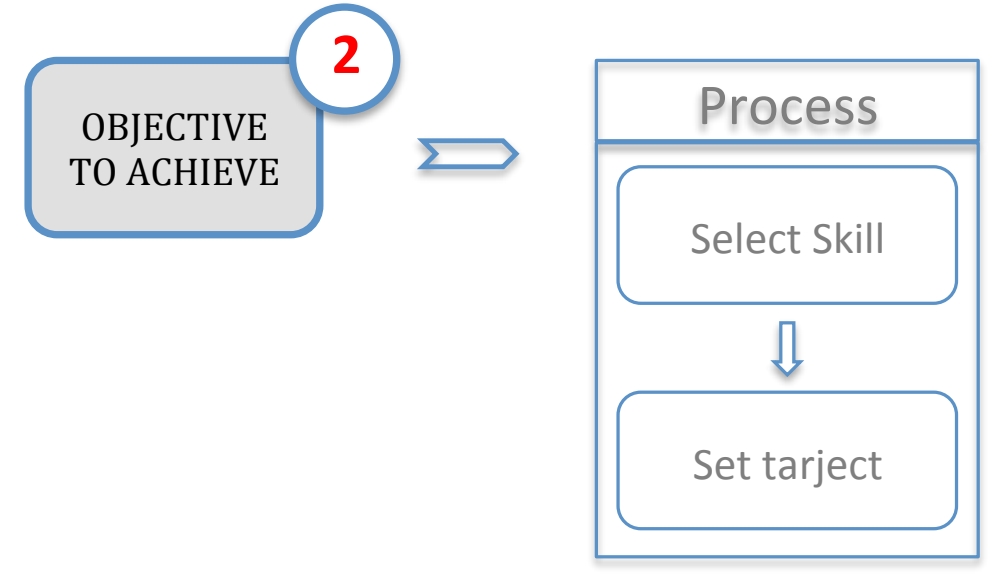

Figure 3. Stage 2: Objective to achieve.

\section{Actions to follow (Figure 4).}

In this last stage, the methodology establishes the set of actions to follow so that the student reaches the level of competence set in the previous stage, either globally or in the selected skill set. For this, a method composed of three sub-stages is used: Training, practice and monitoring. Each of these sub-stages is described below.

- Training: This sub-stage defines two types of training. On the one hand, generic training, referred to the understanding of the fundamentals of effective oral communication. It allows the student to learn, in a theoretical way, the basic foundations of the competence. To do this, the student reviews a series of very short videos in which they are described in a practical and simple way the fundamentals. After the review the student must make a questionnaire that assesses the degree of understanding of these fundamentals. If this grade 
does not reach a certain grade, the student is advised to repeat again the video and then the questionnaire. This generic training is common and identical for all students, regardless of their level of competence. Also, as discussed in the first stage, students who evaluate the presentations should receive this training. The second type of training is of a specific type. In this sense, depending on the target chosen by the student, the tool provides specific training based on videos classified by skills and level of difficulty. Three videos of less than three minutes duration are being developed for each skill. After viewing each video, the tool again proposes an evaluation questionnaire to check if the training is being effective. As with the questionnaires associated with the specific training, if the student does not obtain a minimum score, the student is advised to have a new revision and evaluation.

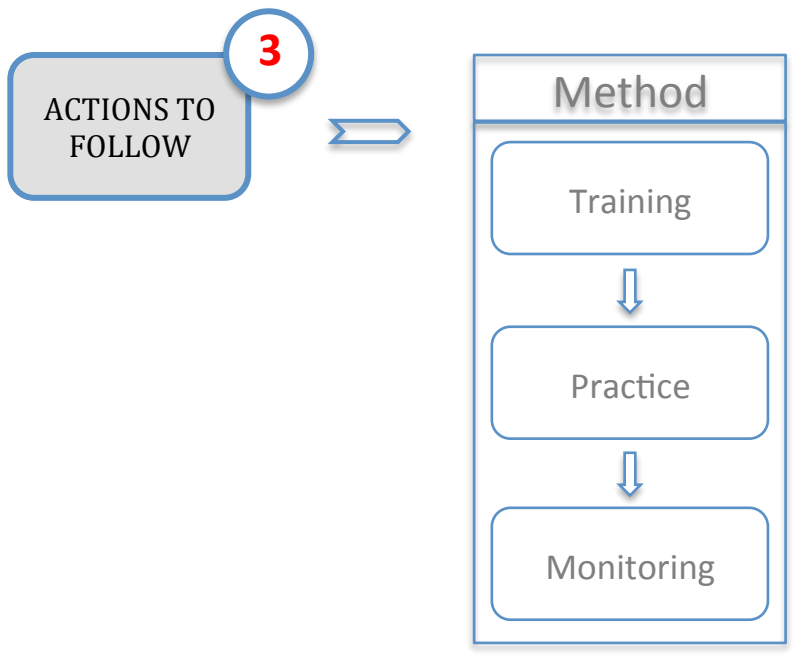

Figure 4. Stage 3: Actions to follow.

- Practice: This sub-stage is used for the implementation of the knowledge acquired in the previous sub-stage. For this, the student makes several presentations. These presentations can be recorded on video, in a personal way and without the need of classmates. The classroom allows the recording of presentations that can later be viewed exclusively by the student or by other colleagues or teachers, according to the choice of the student. This viewing can be evaluated by questionnaires, either exclusively by the student or by those the student wants.

- Monitoring: In this stage, all assessments from the previous stage are monitored through the tool so that the student has a reference about the level acquired. Since the evaluation through recorded videos without public is only part of the learning, it is necessary that, finally, the student returns to make real presentations in class to be able to find out the actual level reached. Thus, the methodology returns to the first stage, repeating the cycle again.

\section{CONCLUSIONS}

It has been presented a methodology to increase the level of effective communication competence in its oral dimension. It is intended for postgraduate students but can be perfectly used for undergraduate students. It is based on a set of simple steps supported by a computer tool to facilitate the information management, and at the same time makes this methodology useful and simple. It is designed to allow a self-assessment of the commented competence, in such a way that it facilitates and increases the individual level of competition.

Its use will not be compulsory, being necessary the collaboration of the students to be able to establish the real degree of its utility. In this sense, it is expected that the master students, as is usually the case, consider their usefulness positive and decide to use it.

At present, the development of the tool is in an advanced stage. The methodology integrated in the tool will be applied during the next academic year in a course of the master in Advanced Engineering Production, Logistics and Supply Chain at the Higher Technical School of Industrial Engineering (Universitat Politècnica de València). 


\section{ACKNOWLEDGEMENTS}

This work has been developed within the research project called "Use of software applications for training and assessing the UPV transversal competence "effective communication" in bachelor and master" (Ref. PIME-A16-16) funded by the Vice-Rectorate for Studies, Quality and Accreditation at Universitat Politècnica de València.

\section{REFERENCES}

[1] A. Villa and M. Poblete, M. “Aprendizaje basado en competencias. Una propuesta para la evaluación de las competencias genéricas". Universidad de Deusto. Bilbao, 2017

[2] A. Blanco. "Desarrollo y Evaluación de competencias en Educación Superior". Madrid: Narcea., 2009.

[3] J.M. Rodríguez-Gomez. "De la noción de calificación a la noción de competencia: sugerencias para el profesorado". Revista Electrónica Interuniversitaria de Formación del Profesorado. 2(2), 93-101. 2009.

[4] M. J. Alsina. "Rúbricas de evaluación de competencias". Cuadernos de docencia universitaria, $\mathrm{n}^{\circ}$ 26. Barcelona: ICE-UB/Octaedro. 2013

[5] A. Villa and M. Poblete. "Aprendizaje Basado en Competencias. Una propuesta para la evaluación de las competencias genéricas. Universidad de Deusto, Bilbao. 2007. 